\title{
An automated online instrument to quantify aerosol-bound reactive oxygen species (ROS) for ambient measurement and health-relevant aerosol studies
}

\author{
Francis P. H. Wragg ${ }^{1}$, Stephen J. Fuller ${ }^{1}$, Ray Freshwater ${ }^{1}$, David C. Green ${ }^{2}$, Frank J. Kelly ${ }^{2}$, and Markus Kalberer ${ }^{1}$ \\ ${ }^{1}$ Department of Chemistry, University of Cambridge, Lensfield Road, Cambridge CB2 1EW, UK \\ ${ }^{2}$ MRC-PHE Centre for Environment and Health, King's College London, Franklin-Wilkins Building, \\ 150 Stamford Street, London SE1 9NH, UK
}

Correspondence to: Markus Kalberer (markus.kalberer@atm.ch.cam.ac.uk)

Received: 27 May 2016 - Published in Atmos. Meas. Tech. Discuss.: 23 June 2016

Revised: 14 September 2016 - Accepted: 18 September 2016 - Published: 6 October 2016

\begin{abstract}
The adverse health effects associated with ambient aerosol particles have been well documented, but it is still unclear which aerosol properties are most important for their negative health impact. Some studies suggest the oxidative effects of particle-bound reactive oxygen species (ROS) are potential major contributors to the toxicity of particles. Traditional ROS measurement techniques are labour-intensive, give poor temporal resolution and generally have significant delays between aerosol sampling and ROS analysis. However, many oxidising particle components are reactive and thus potentially short-lived. Thus, a technique to quantify particle-bound ROS online would be beneficial to quantify also the short-lived ROS components.

We introduce a new portable instrument to allow online, continuous measurement of particle-bound ROS using a chemical assay of $2^{\prime} 7^{\prime}$-dichlorofluorescein (DCFH) with horseradish peroxidase (HRP), via fluorescence spectroscopy. All components of the new instrument are attached to a containing shell, resulting in a compact system capable of automated continuous field deployment over many hours or days.

From laboratory measurements, the instrument was found to have a detection limit of $\sim 4 \mathrm{nmol}\left[\mathrm{H}_{2} \mathrm{O}_{2}\right]$ equivalents per cubic metre $\left(\mathrm{m}^{3}\right)$ air, a dynamic range up to at least $\sim 2000 \mathrm{nmol}\left[\mathrm{H}_{2} \mathrm{O}_{2}\right]$ equivalents per $\mathrm{m}^{3}$ air and a time resolution of $\leq 12 \mathrm{~min}$. The instrument allows for $\sim 16 \mathrm{~h}$ automated measurement if unattended and shows a fast response to changes in concentrations of laboratory-generated oxidised organic aerosol. The instrument was deployed at an urban site in London, and particulate ROS levels of up to
\end{abstract}

$24 \mathrm{nmol}\left[\mathrm{H}_{2} \mathrm{O}_{2}\right]$ equivalents per $\mathrm{m}^{3}$ air were detected with $\mathrm{PM}_{2.5}$ concentrations up to $28 \mu \mathrm{g} \mathrm{m}^{-3}$.

The new and portable Online Particle-bound ROS Instrument (OPROSI) allows fast-response quantification; this is important due to the potentially short-lived nature of particlebound ROS as well as fast-changing atmospheric conditions, especially in urban environments. The instrument design allows for automated operation and extended field operation with twice-daily presence of an operator. As well as having sensitivity suitable for ambient level measurement, the instrument is also suitable at concentrations such as those required for laboratory and chamber toxicological studies.

\section{Introduction}

The adverse health effects associated with atmospheric aerosol particles have been well documented in epidemiological studies and further supported with biological cell culture/in vivo studies; there is a widely accepted association between higher ambient aerosol particle levels and increases in hospital admissions and deaths due to respiratory disease, cardiovascular disease and cancer (Brunekreef and Holgate, 2002; Dockery et al., 1993; Kunzi et al., 2013; Laden et al., 2006; Lepeule et al., 2012). Due to the large variability in ambient particulate matter, it is still unclear which physical or chemical properties are most important for these negative health effects. Previous studies have suggested particle size, transition metal levels and elemental carbon levels to be bet- 
ter indicators than simple particle mass concentration (Godri et al., 2010; Kelly and Fussell, 2012; Koike and Kobayashi, 2006; Oberdorster et al., 2005).

For example, particle size has been strongly correlated with negative health effects due to increased deposition in the alveolar region of the lung, specialised for gas exchange and lacking the cilia-hair clearance system found in the upper respiratory system. Particles with aerodynamic diameter smaller than $2.5 \mu \mathrm{m}\left(\mathrm{PM}_{2.5}\right.$ hereafter) are more likely to deposit in this susceptible lower region of the lung than larger particles are, thus increasing their likely health impact (Oberdorster et al., 2005).

A number of previous studies have highlighted the oxidising capacity of particulate matter as being a potential major cause of their toxicity, particularly with reference to particle-bound or particle-induced reactive oxygen species (ROS), defined here as including families of oxygen-centred or oxygen-related free radicals (e.g. $\mathrm{HO}^{*}, \mathrm{HOO}^{\circ}$ or ROO'), ions (e.g. HOO-) and molecules (e.g. $\mathrm{H}_{2} \mathrm{O}_{2}$, organic and inorganic peroxides) with oxidising properties (Borm et al., 2007; Donaldson et al., 2003; Kramer et al., 2016; MacNee and Donaldson, 2003; Morio et al., 2001; Pryor and Church, 1991; Stevanovic et al., 2013; Wang et al., 2013). It has been argued that deposition of aerosol-bound ROS in the lung, or ROS generation upon particle deposition in the lung, can lead to a depletion of anti-oxidants naturally present in the lung-lining fluid. This depletion, defined as oxidative stress, can result in an immune response, such as inflammation and proliferation of defence cells. Subsequent cell damage and chronic inflammation may result in increased prevalence of disease, e.g. chronic obstructive pulmonary disease, asthma and cardiovascular disease (Brunekreef and Holgate, 2002; Dockery et al., 1993; Hart et al., 2015; Lepeule et al., 2012; Oberdorster et al., 2005; Puett et al., 2014).

Whether it be the formation of ROS in situ after particle deposition in the respiratory tract (e.g. through the interaction with transition metal ions and inorganic aerosol) or ROS that are already present on respirable particles to which we are exposed (e.g. organic radicals or peroxides), cell culture studies show there is correlation between the overall oxidative capacity of aerosol particles and their negative effect on human health (Brunekreef and Holgate, 2002; Steenhof et al., 2011; Tong et al., 2016).

Little is known about ROS in the organic fraction of ambient aerosol, despite the fact that they often make up more than $50 \%$ of submicron aerosol mass (Jimenez et al., 2009). A potential major contributor to PM-induced health concerns could be water-soluble particle-bound ROS (e.g. peroxides, hydroperoxides, peroxy acids or radicals) in the organic aerosol fraction. A number of studies have attempted to estimate total peroxide content in organic aerosols, leading to the conclusion that peroxides are a significant fraction (10 to $>50 \%$ ) of aged, oxidised, i.e. atmospherically processed, organic aerosol (Docherty et al., 2005; Hasson and Paulson, 2003; Kramer et al., 2016; Mertes et al., 2012; Vesna et al.,
2009; Ziemann, 2005). A main difficulty in analysing organic peroxides and ROS in general in aerosols is the lack of appropriate analytical methods for a reliable quantification.

It could be argued that the most representative measure of PM-related negative health effects would be via direct in vivo or in vitro exposure. However, these methods are limited by a number of factors, including expense, ethics, required measurement timescale, limited suitability for field studies and often the requirement to collect large amounts of aerosol mass. Alternatively, chemical, acellular, detection methods can provide suitable proxies for the effect of exposure to living tissue. The advantages of such acellular detection methods include reduced labour, increased portability especially for field studies, and increased adaptability to different sources and conditions. Chemical combinations can be adjusted to focus on different chemical properties potentially linked to the health effects of aerosol. If coupled with biological aerosol exposure methods, this ability to select and measure specific chemical properties should allow comparisons to overall toxicity to living tissue, ultimately providing information about which chemical properties are most closely linked to aerosol toxicity.

Traditional offline acellular aerosol sampling methods for ROS analysis rely on particles being collected on filters or impactors, followed by subsequent solvent extraction steps and chemical analysis, and can often take hours to days from sample collection to analysis, or substantially longer if storage steps are also considered (Godri et al., 2011; Venkatachari et al., 2005; Verma et al., 2011). But ROS are often not stable or long-living (e.g. $\mathrm{ROOH}, \mathrm{R}, \mathrm{RO}_{x}$ species in particular), so such slow and time-consuming offline processes may not be best suited to determine their atmospheric concentrations, leading to potentially significant underestimates of ROS concentrations. This is supported by an earlier study in which we showed ROS concentrations in laboratorygenerated oxidised organic aerosol decreased by a factor of 5-10 within 15 min of collection of a sample on a filter, suggesting offline techniques may fail to capture the short-lived, labile, fraction of ROS, instead capturing only the longerlived, less labile, fraction (Fuller et al., 2014). Further shortfalls of offline techniques include typical procedures remaining labour- and resource-intensive, and the resulting data having poor temporal resolution. Thus, faster, online techniques would be more suited for reliable quantification of these reactive species.

Attempts have been made to create systems with improved temporal resolution relative to offline filter techniques. Wang et al. (2011) and King and Weber (2013) built systems utilising the established fluorescence probe $2^{\prime} 7^{\prime}$ dichlorofluorescein (DCFH) in conjunction with catalytic enzyme horseradish peroxidase (HRP) via fluorescence spectroscopy. The Wang et al. (2011) system includes the Particle Into Liquid Sampler as a central component, which relies upon introduction of steam of at least $100^{\circ} \mathrm{C}$. This could 


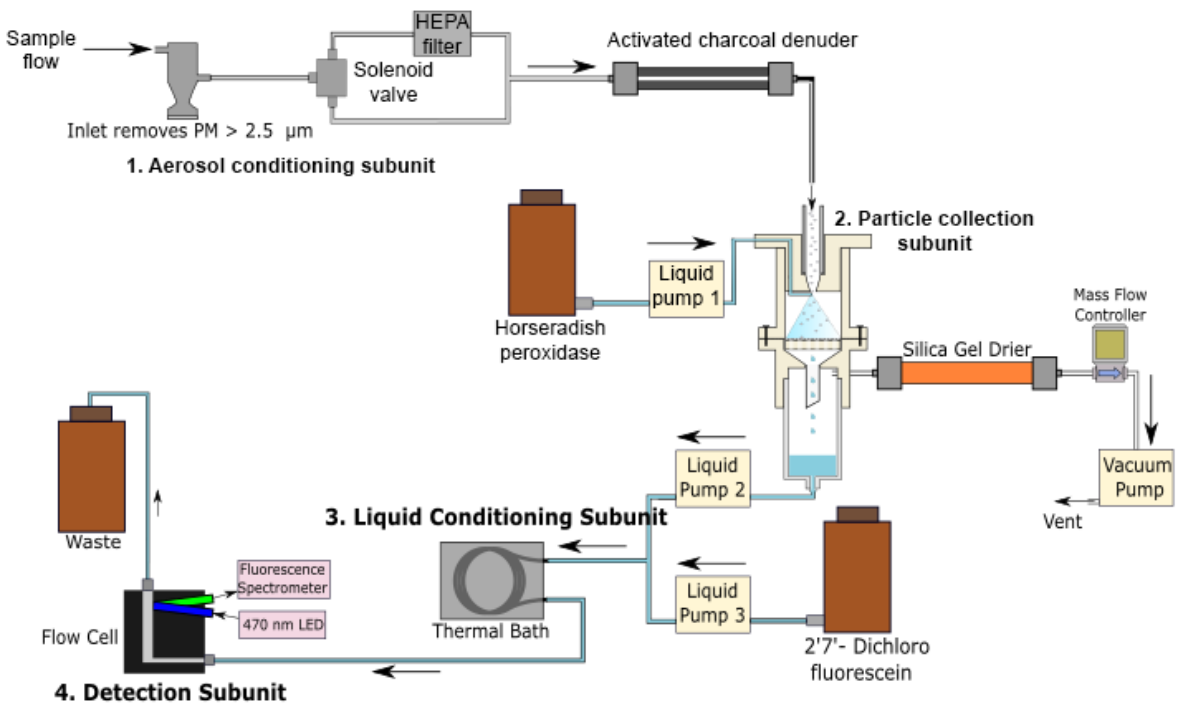

Figure 1. Schematic diagram of the new portable Online Particle-bound ROS Instrument (OPROSI), comprising four labelled subunits: (1) the aerosol-conditioning subunit enables removal of particles $>2.5 \mu \mathrm{m}$, automated blank measurement and removal of gases such as volatile organic compounds and ozone; (2) the particle collection subunit allows collection of particles into liquid phase, allowing soluble ROS to be extracted; (3) the liquid-conditioning subunit provides suitable time and temperature for the reaction between the DCFH-HRP assay and extracted ROS components; and (4) the detection subunit records fluorescence intensity of the assay upon reaction with the sample.

interact with highly reactive and labile species, potentially introducing artefacts into the ROS measurement.

We further developed the technique by Wang et al. (2011) and introduced mild ROS extraction conditions during particle collection, thus reducing potential artefacts due to decomposition of labile ROS components at elevated extraction temperatures (Fuller et al., 2014). The described system allowed online measurement with a particle collector that enabled samples to be scavenged by the assay within seconds of entering the system, increasing the likelihood of very short lived ROS also being quantified.

This study describes significant further development and integration of our online ROS quantification technique into a compact and portable online ROS instrument capable of automated, continuous, multi-hour, highly time-resolved measurement suitable for extended field deployment.

\section{Methods}

The new Online Particle-bound ROS Instrument (OPROSI) comprises four main subunits, as depicted in Fig. 1. The aerosol-conditioning subunit enables automated blank measurement, removal of particles $>2.5 \mu \mathrm{m}$ and removal of gases such as volatile organic compounds and ozone; the particle collection subunit allows collection of particles into liquid phase, allowing water-soluble ROS to be extracted; the liquid-conditioning subunit provides suitable time and temperature for the reaction between the DCFH-HRP assay and extracted ROS components; and the detection subunit records fluorescence intensity of the assay upon reaction with the sample. A more detailed description of the instrument and its performance is given below but is preceded by a brief description of the chemical reaction system used to quantify ROS (further detail of the chemical system is provided in Fuller et al., 2014).

The chemical reaction system used to detect ROS is based on the reaction of ROS with HRP (Type VI, Sigma Aldrich, 1 unit $\mathrm{mL}^{-1}, 10 \%$ phosphate buffer solution (PBS)). An aqueous HRP solution is pumped at $1 \mathrm{~mL} \mathrm{~min}^{-1}$ into the particle collector (Fig. 1). In the particle collector the HRP solution spray is mixed with the airflow continuously pumped through the particle collector. Water-soluble ROS in aerosol particles are extracted and react with HRP. This particle extract/HRP solution is pumped away and then combined with an aqueous DCFH solution $(10 \mu \mathrm{M}, 10 \% \mathrm{PBS})$, also pumped at $1 \mathrm{~mL} \mathrm{~min}^{-1}$, and the combined mixture passes through a reaction coil (heated to $40^{\circ} \mathrm{C}$ ) for $10 \mathrm{~min}$, where the concentrations of DCFH and HRP are now $5 \mu \mathrm{M}$ and 0.5 units $\mathrm{mL}^{-1}$, respectively, and where the oxidised HRP reacts with DCFH, yielding fluorescent product DCF. The solution is then pumped through the fluorescence spectroscopy continuous-flow cell to quantify the amount of DCF generated, which correlates with the amount of ROS extracted from the aerosol particles.

All of the instrument components in Fig. 1 are bolted within or onto a metal shell $60 \times 50 \times 25 \mathrm{~cm}$ in size (adapted from a RS wall-mounted enclosure), with the vacuum pump being the exception, to avoid vibrations within the instrument. Figure $2 \mathrm{a}$ and $\mathrm{b}$ show photographs of the instrument and all components therein. Figure 2a shows the exterior, to 


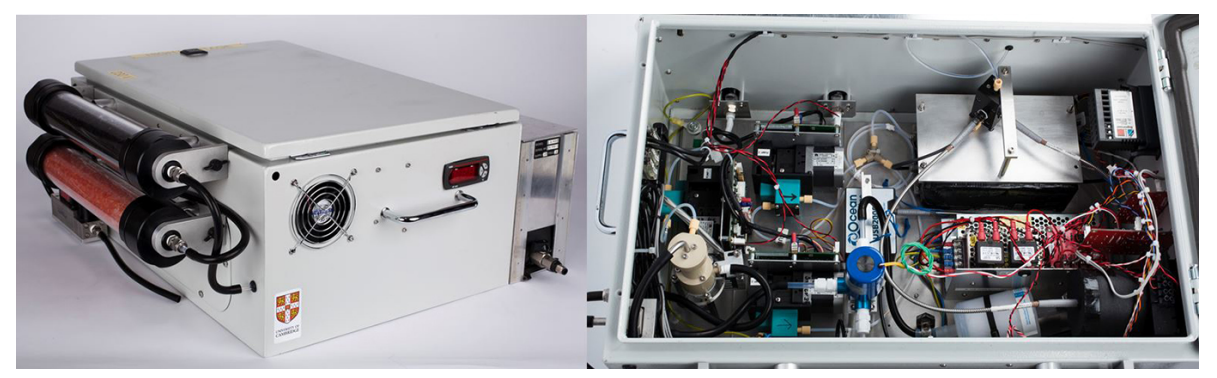

Figure 2. The exterior (a) and interior (b) of the new OPROSI. All components shown are attached and integrated into, or onto, a portable box $(60 \times 50 \times 25 \mathrm{~cm})$ to allow easier deployment for field studies.

which the charcoal denuder, silica gel drier and mass flow controller are attached. The silver compartment to the right is the liquid enclosure, separating large quantities of liquid from the electronics found inside the main enclosure. This separate compartment also allows chemical containers to be refilled and the waste container to be emptied without needing to open the main enclosure lid, thus reducing disturbance of the instrument's internal conditions during continuous measurement; the chemical containers can be filled directly from openings at the top, and the waste container can be emptied using the waste tap visible in the bottom right of Fig. 2a. The chemical containers connect to the pumps of the liquid system in the main enclosure via quick-release connections, allowing for quick and easy removal for cleaning or refilling.

Figure $2 \mathrm{~b}$ shows the interior of the instrument. Conditions are stable and standardised between different experiments as a result of this enclosed set-up, giving increased temperature stability, better maintained dark conditions and no positional changes of components. Another important benefit of the compact and fixed shell structure is relatively easy movement of the instrument between measurement locations for laboratory or field experiments.

Aerosol samples are drawn into the instrument at $5 \mathrm{~L} \mathrm{~min}^{-1}$ through the aerosol-conditioning unit, which consists first of a stainless-steel cyclone $(2.5 \mu \mathrm{m}$ cut-off at $5 \mathrm{~L} \mathrm{~min}^{-1}$, URG-2000-30E-5-2.5-S, URG), thus removing particles $>2.5 \mu \mathrm{m}$ from the sampled air. The sample then comes to a three-way solenoid valve (M443W2DFS-LV-132, IPS) which can be controlled to send the sample flow down one of two routes. One route, normally open, leads straight to a custom-built activated-charcoal denuder (NORIT ${ }^{\circledR}$ SUPRA pellets, Sigma Aldrich), which removes oxidising gases, before the flow is then directed to the particle collector. The second route, normally closed, leads to a high-efficiency particulate air filter (HEPA CAP 75, Whatman), which removes aerosol particles before re-joining the original route prior to the charcoal denuder. This second route allows for blank measurements to be taken in order to account for fluorescence that is not due to aerosol-bound ROS. As the solenoid valve can be controlled via computer software, blank mea- surements can be started and stopped automatically at timed intervals, e.g. during long unattended experiments, to assess whether the blank/background fluorescence changes with time.

After passing through the charcoal denuder, the aerosol particles enter the custom-built particle collector, described in detail in Fuller et al. (2014) and based on designs by Takeuchi et al. (2005). The particle collector allows the extraction of water-soluble components of aerosol under mild conditions (i.e. room temperature) and within seconds of entering the particle collector. In the particle collector (PEEK) the aerosol sample flow $\left(5 \mathrm{~L} \mathrm{~min}^{-1}\right)$ is combined with the flow of liquid horseradish peroxidase $\left(1 \mathrm{~mL} \mathrm{~min}^{-1}\right)$ to form a fine spray of collection solution (Fig. 3). Should watersoluble ROS not be extracted at the initial spray-formation stage, they will further come into contact with the HRP solution at the filter stage within the particle collector. This consists of a paper filter $(25 \mathrm{~mm}$, Whatman Type 1) resting on a PEEK mesh support to assure a constant and uniformly wet filter. From the liquid catchment area, adapted from a glass syringe, the combined HRP and aerosol extract solution is pumped away continuously to be later combined with DCFH. At an air flow rate of $5 \mathrm{~L} \mathrm{~min}^{-1}$ and liquid flow rate of $1 \mathrm{~mL} \mathrm{~min}^{-1}$, the particle collector has an efficiency greater than $95 \%$ for aerosol particles $>100 \mathrm{~nm}$, falling to $50 \%$ for $50 \mathrm{~nm}$ particles (Fuller et al., 2014).

For automation of the particle collector subunit to be achieved, the liquid height must remain constant in the catchment syringe regardless of potential fluctuation or drift in flows from pumps 1 and 2 . This ensures the extracted sample keeps a constant liquid volume, and thus mixing and reaction time, within the catchment syringe. A new method is introduced to provide an automated process for maintaining this constant volume. Figure 3 describes the new addition of optical sensors (OPB720, Optek) alongside the catchment syringe, which, when coupled with a chemically inert reflective floating object at the liquid-air barrier, allows the liquid level height to be detected and subsequently controlled via feedback to pump 1 settings. The device is made from chemically inert Teflon and is torus-shaped to reduce interference with falling liquid extract drops. The instrument uses three 


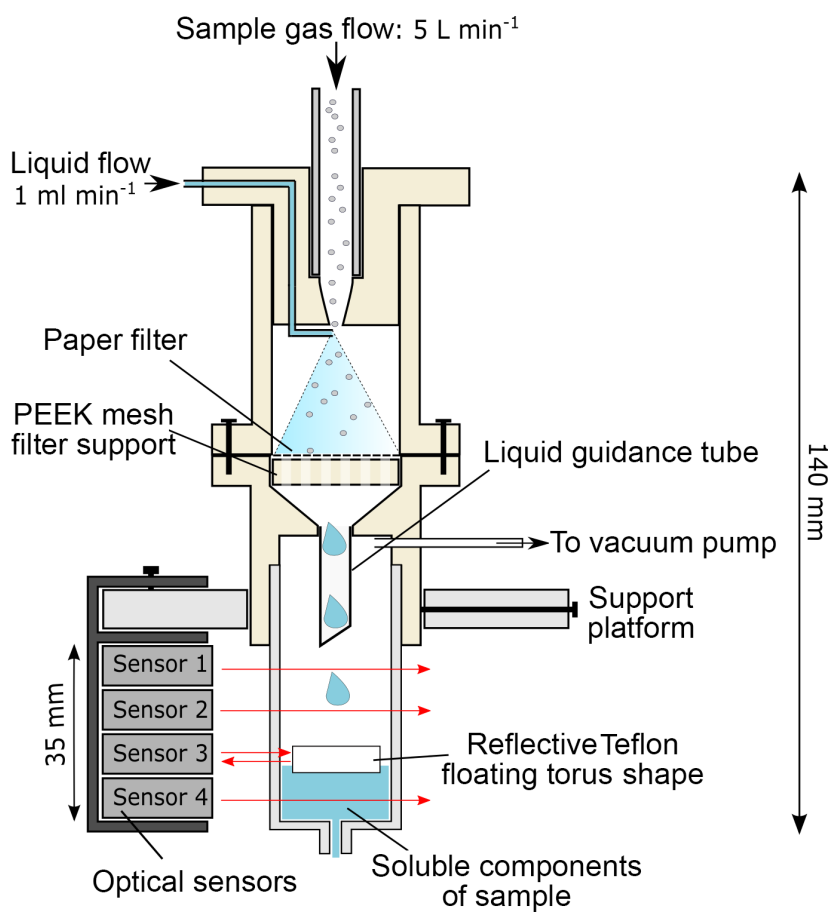

Figure 3. Schematic diagram of the particle collector allowing collection of particle-bound, water-soluble ROS components under mild extraction conditions. Addition of the reflective optical sensor system allows liquid height to be detected, controlled and kept constant, thus allowing automated measurement for extended periods of time under constant reaction conditions.

identical diaphragm pumps (STEPDOS 03, KNF) to pump the HRP solution, the aerosol extract and the DCFH solution, as indicated in Fig. 1.

After the particle collector, the aerosol extract/HRP solution $\left(1 \mathrm{~mL} \mathrm{~min}^{-1}\right)$ is combined with the DCFH solution $\left(1 \mathrm{~mL} \mathrm{~min}^{-1}\right)$, as shown in Fig. 1. The liquid flow then enters a thermally stabilised Teflon reaction coil $(3.175 \mathrm{~mm}$ OD, $1.5 \mathrm{~mm}$ ID) where the DCFH reacts with the HRP for $10 \mathrm{~min}$ in a sealed ethylene glycol bath (heated to $40^{\circ} \mathrm{C}$ ), leading to the production of fluorescent dye DCF. The bath is heated using an externally applied heat pad and controlled using a proportional-integral-derivate (PID) controller (Vemer thermoregulator) and an internal, liquid-resistant, thermistor (NTC liquid probe, $150 \mathrm{c}, \mathrm{RS}$ ). A second thermistor $(10 \mathrm{~K} 3 \mathrm{~A} 1)$ is placed on the external surface of the bath to track the temperature data. The bath is surrounded with insulation foam to retain heat and reduce temperature fluctuations.

The solution is then pumped through a custom-built continuous-flow fluorescence spectroscopy cell to quantify the DCF formed in the reaction coil. The flow cell (black acetate) has a vertical flow channel $(5 \mathrm{~mm}$ diameter, $0.6 \mathrm{~mL}$ total volume) where excitation light from a light-emitting diode (LED) ( $470 \mathrm{~nm}$, Luxeon Rebel Star on CoolBase) is delivered via an optic fibre and collimating lens (Ocean Optics) through a quartz rod $(25 \mathrm{~mm} \times 3 \mathrm{~mm}$, UQG OPTICS $)$. Fluorescent emission by DCF at $522 \mathrm{~nm}$ is transferred via another quartz rod, collimating lens and optical fibre coupled to an optical spectrometer (Ocean Optics USB2000+; 200$800 \mathrm{~nm}$ ). The quartz rods act as light channels between the sample flow channel and the collimating lens-optical fibre coupling. The flow channel is vertical at the detection point to allow any air bubbles to pass this point as quickly as possible and reduce potential disturbance of the continuous fluorescence detection.

The LED source is mounted directly onto the cold plate of a thermoelectric cooler (TECooler) heat pump assembly (Thermo Electric Devices) to maintain the LED system at a constant temperature. The cold plate and LED are enclosed in a black acetate enclosure and insulating foam, reducing heat transfer to surroundings. The heat pump removes excess heat via a fan. This also circulates external air through the instrument to reduce its internal temperature.

All data obtainment and electronic hardware control are enabled using LabVIEW (National Instruments) and a laptop. A multi-channel voltage data logger (1216 series PicoLog, PICO Technologies) is used to collect analogue data from the thermal bath, TECooler, various instrument thermistors and the syringe optical sensors. It also allows digital control of the solenoid valve and LED driver. All electrical components are powered by USB interface with the laptop, or else via compact and enclosed power supplies (Traco Power TXM Series, TDK Lambda LS Series) fed by one standard mains plug.

\section{Results}

\subsection{Response of chemical assay to atmospherically relevant compounds}

Calibration of the instrument's chemical assay, liquidconditioning and detection systems is achieved using aqueous solutions of known concentrations of ROS model hydrogen peroxide $\left(\mathrm{H}_{2} \mathrm{O}_{2}\right)$. The standard calibration set-up is adjusted from that shown in Fig. 1, to bypass the aerosolconditioning unit and the particle collector: Teflon tubing connects the HRP bottle directly to pump 2; the DCFH bottle is replaced by a series of $20 \mathrm{~mL}$ vials containing DCFH (same concentration as described before) and $\mathrm{H}_{2} \mathrm{O}_{2}$ (varying concentrations). For $\mathrm{H}_{2} \mathrm{O}_{2}$ calibration, the instrument runs continuously while different $\mathrm{H}_{2} \mathrm{O}_{2}$ concentrations are introduced by switching vials every $15 \mathrm{~min}$. Figure 4 shows an example of data obtained from such an experiment, with $\mathrm{H}_{2} \mathrm{O}_{2}$ solutions at $0.025-1.0 \mu \mathrm{M}$. The error bars show the standard deviation of data obtained at each concentration. This method allows calibration to take place with minimal changes to the fixed instrument, requiring only the addition of a single piece of Teflon tubing within the main enclosure, thus increasing 


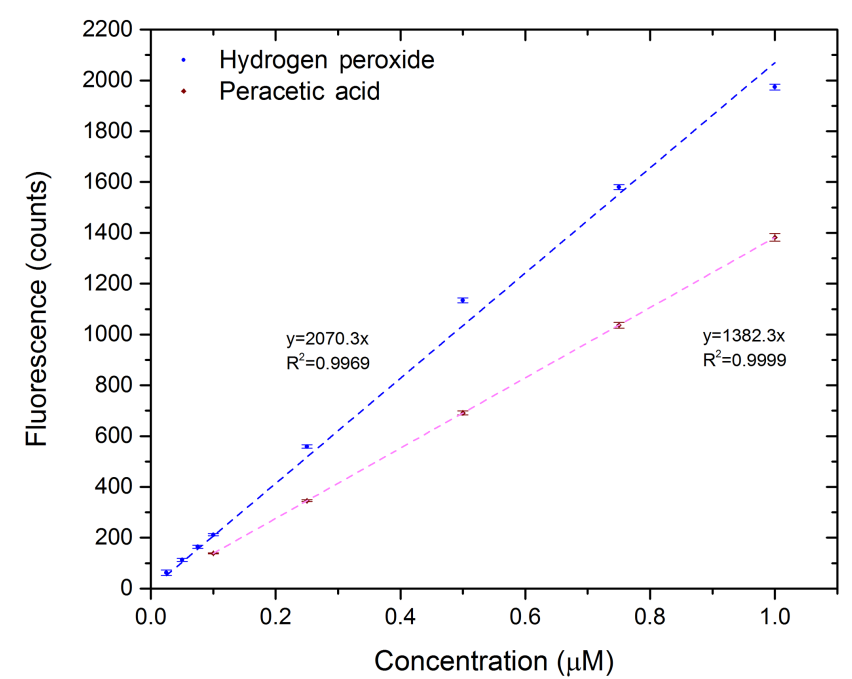

Figure 4. Example OPROSI calibration plot with standard ROS compound hydrogen peroxide and peroxide peracetic acid.

the ease with which calibration can be performed under field measurement conditions.

Using the same method, the DCFH-HRP assay has been tested with, and responded positively to, other water-soluble ROS compounds (organic peroxides and peracids) such as peracetic acid and tert-butyl hydroperoxide. The response to peracetic acid, also shown in Fig. 4, was found to be $1.50 \pm$ 0.03 times weaker than that to $\mathrm{H}_{2} \mathrm{O}_{2}$. The assay response to tert-butyl hydroperoxide was found to be $19.30 \pm 2.05$ times weaker than that to $\mathrm{H}_{2} \mathrm{O}_{2}$. The assay showed no response to acetic acid (tested up to $100 \mu \mathrm{M}$ ), a non-ROS carboxylic acid compound, suggesting similar non-ROS compounds in aerosol particles would not affect the assay's reactivity.

It should be noted that this continuous-flow system provides an effective time limit to the reaction; the measured reaction will only occur within the $10-15 \mathrm{~min}$ before the flow reaches the fluorescence detection point. If the response of the assay to a particular species is too slow, the reaction between species and assay may not reach completion before the flow enters the detection cell. Using no-flow systems, this 10-15 min was found to be adequate for quick-reacting species such as $\mathrm{H}_{2} \mathrm{O}_{2}$ and peracetic acid. However, sterically protected peroxy groups, such as those found in tert-butyl hydroperoxide, reacted more slowly. Therefore, the ROS signal measured in aerosol samples of unknown ROS composition should be interpreted as quantification mainly of the fast-reacting ROS fraction, with slowly reacting ROS components contributing less to the overall measured ROS concentration.

\subsection{Laboratory measurement of oxidised secondary organic aerosol}

In an experiment to show the measurement capability of the instrument over an extended period of several hours, a flowtube system was used to create oxidised secondary organic aerosol (SOA) via ozonolysis of $\alpha$-pinene. This is a wellestablished and reliable method to create SOA with constant concentrations over many hours (Kroll and Seinfeld, 2008; Lee et al., 2006). A schematic of the system used is shown in Fig. 5, and results are given in Fig. 6.

As shown in Fig. 5, ozone was generated by passing synthetic air (zero-grade synthetic air, BOC), $0.3 \mathrm{~L} \mathrm{~min}^{-1}$, over an ozone-generating ultraviolet (UV) lamp (SOG1, $184 \mathrm{~nm}$ ), exposure to which was adjusted via an internal UV shield. This flow was combined with a flow of $\alpha$-pinene-laden synthetic air, $0.3 \mathrm{~L} \mathrm{~min}^{-1}$, in a $2 \mathrm{~L}$ glass tube, giving a reaction time of $\sim 5 \mathrm{~min}$, leading to the formation of $\alpha$-pinene SOA. The oxidised aerosol was then passed through an activated charcoal denuder to remove excess ozone and organic gaseous species. This was put in place in addition to the permanent denuder of the instrument in order to reduce the possibility of saturation at unusually elevated ozone concentrations over many hours. The SOA flow was then diluted with nitrogen, $5 \mathrm{~L} \mathrm{~min}^{-1}$. Particle-bound ROS measurements via the OPROSI were performed in parallel with particle size distribution measurements using a scanning mobility particle sizer (SMPS), allowing comparison between changes in aerosol mass and changes in reported aerosol ROS content.

The fluorescent spectrometer recorded an average of 100 spectra $(200-800 \mathrm{~nm})$ every $1.0-1.5 \mathrm{~s}$. The SMPS recorded scans every 3 min and comprised a TSI model 3081 differential mobility analyser (DMA) and a 3776 condensation particle counter (CPC), set to a sampling rate of $0.3 \mathrm{~L} \mathrm{~min}^{-1}$ and a DMA sheath flow of $3.0 \mathrm{~L} \mathrm{~min}^{-1}$. Particle number size distribution data (14-670 nm) were obtained using TSI AIM software and converted to particle mass concentration using $1 \mathrm{~g} \mathrm{~cm}^{-3}$ as the assumed density of the oxidised aerosol.

Figure 6 shows data from this $\alpha$-pinene ozonolysis experiment, demonstrating operation over $\sim 5.5 \mathrm{~h}$ and with varying aerosol concentration $\left(\sim 9-120 \mu \mathrm{g} \mathrm{m}^{-3}\right)$. The dotted red line shows the SOA mass concentration values obtained by the SMPS, and the black line shows OPROSI fluorescence intensity due to ROS components in the extracted aerosol sample. The bulk of the experiment shows how the instrument responds to changing total aerosol mass concentration (achieved by altering the exposure to the UV lamp). Increased aerosol mass, via increased lamp exposure and thus increased oxidised SOA formation, leads to an increased fluorescence reading.

The shaded areas in this period correspond to times when the HEPA filter was put in line in the aerosol-conditioning unit, described above and shown in Fig. 1. During these periods, any aerosol, and thus any aerosol-bound ROS, is removed from the sample after entering the instrument, reduc- 


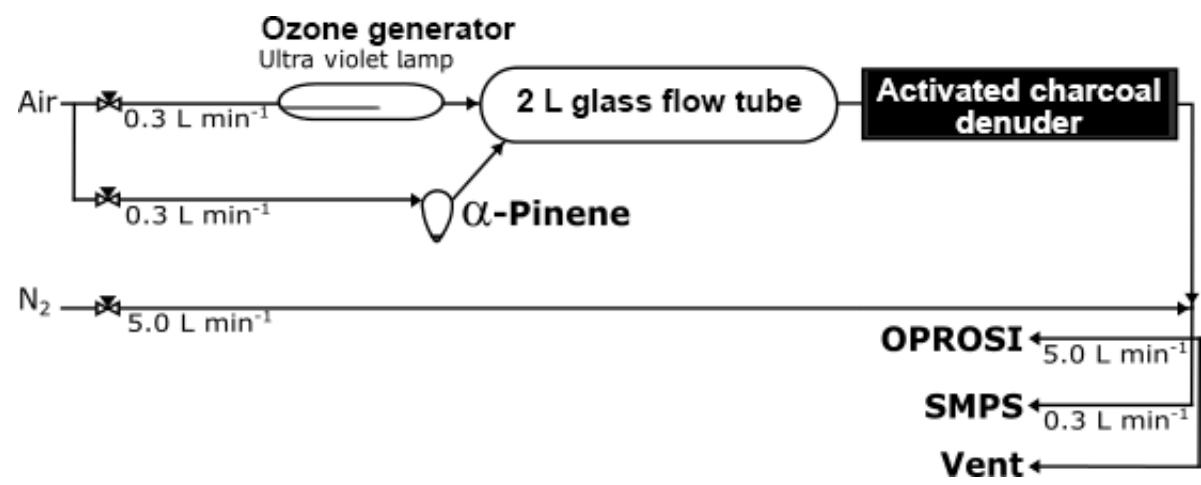

Figure 5. Experimental set-up to produce and measure varying concentrations of oxidised secondary organic aerosol (SOA) via ozonolysis of $\alpha$-pinene. An ozone-generating lamp was used to enable generation of $\alpha$-pinene SOA in the flow tube. The exposure of the lamp was adjustable with an internal UV shield, enabling a range of aerosol masses to be measured and tested for ROS concentration.

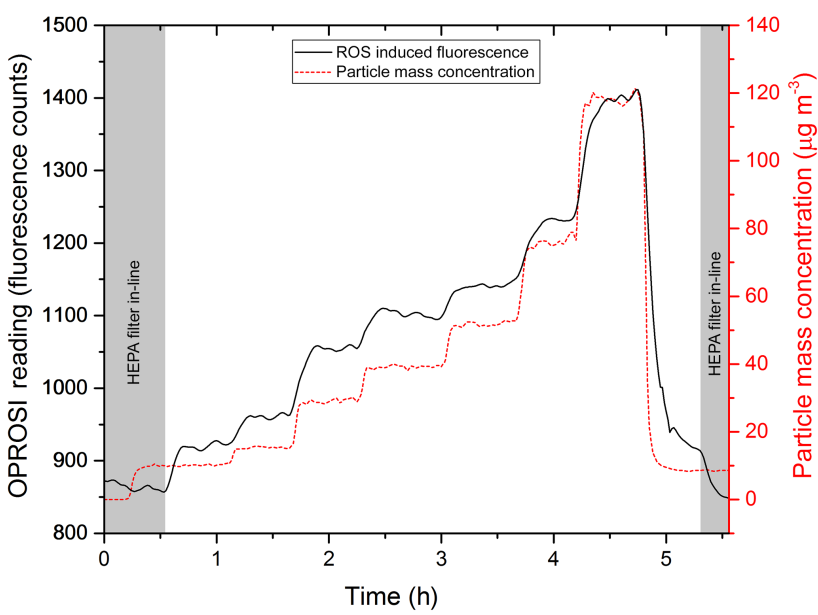

Figure 6. Data from $\alpha$-pinene ozonolysis SOA laboratory experiment, showing the OPROSI response to changes in mass concentration of oxidised aerosol. The time periods highlighted in grey were when a HEPA filter was in line, resulting in an OPROSI blank measurement.

ing the fluorescence reading to blank levels. Over a number of different tests with similar experimental systems, the OPROSI was found functional with tested values up to $425 \mu \mathrm{g} \mathrm{m}^{-3}$ oxidised SOA and $\sim 2000 \mathrm{nmol}\left[\mathrm{H}_{2} \mathrm{O}_{2}\right]$ equivalents per $\mathrm{m}^{3}$ air. The automated process of switching between sample measurement and blank measurement over a period of many hours gave repeatable values with good stability and variability. Full liquid bottles provide $\sim 16 \mathrm{~h}$ of measurement, which can be split between blank and sample measurement, depending on the specific requirements of each experiment. When measuring unknown samples of aerosol-bound ROS for long periods of time, occasional blank measurements should be taken to follow trends in their values. For example, a $16 \mathrm{~h}$ total measurement time period could consist of $12-14 \mathrm{~h}$ sample measurement and 2-4h blank measurement. Potential time-dependent discrepancies between dif-

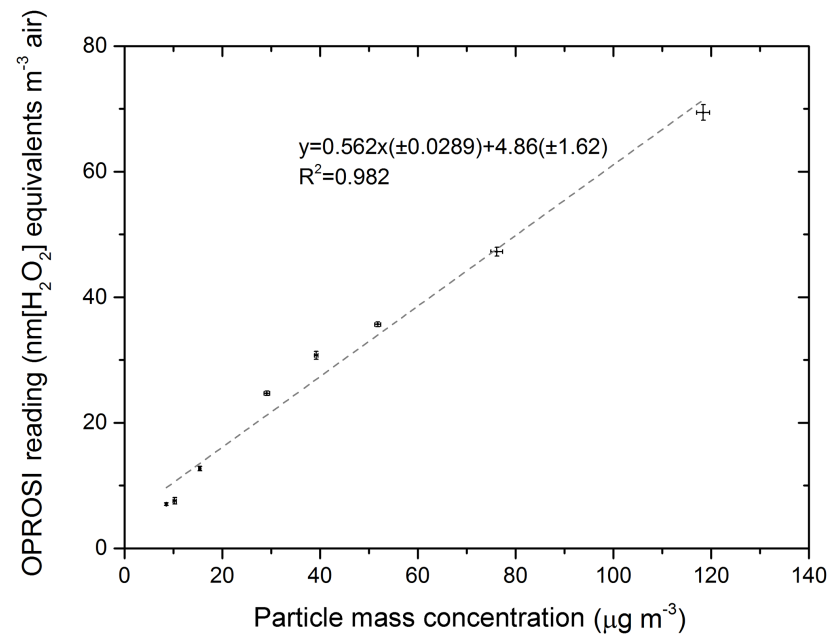

Figure 7. ROS concentration (OPROSI) compared with mass concentration of $\alpha$-pinene SOA particles (SMPS). Increased mass concentration of oxidised SOA was found to correlate with increased ROS concentration.

ferent blank measurement periods could derive from e.g. a drifting of assay reactivity over time or from charcoal denuder efficiency lessening over time.

Raw fluorescence data were then blank-subtracted and converted from fluorescence units (counts) into ROS concentration units (nmol $\left[\mathrm{H}_{2} \mathrm{O}_{2}\right]$ equivalents per $\mathrm{m}^{3}$ air) using data from a $\mathrm{H}_{2} \mathrm{O}_{2}$ calibration curve (Fig. 4), the gas flow rate at the particle collector and the liquid flow rate at the detection point, via Eq. (1):

$\operatorname{ROS}$ Conc $\left(\mathrm{nmol}\left[\mathrm{H}_{2} \mathrm{O}_{2}\right]\right.$ equiv. $\mathrm{m}^{-3}$ air $)=$

$\frac{\operatorname{ROS} \text { Conc }\left(\mathrm{nmol}\left[\mathrm{H}_{2} \mathrm{O}_{2}\right] \text { equiv. } \mathrm{L}^{-1}\right) \times \text { liquid flow rate }\left(\mathrm{L} \mathrm{min}^{-1}\right)}{\text { gas flow rate }\left(\mathrm{m}^{3} \mathrm{~min}^{-1}\right)}$.

Figure 7 shows ROS concentration, in $\mathrm{nmol}\left[\mathrm{H}_{2} \mathrm{O}_{2}\right]$ equivalents per $\mathrm{m}^{3}$ air, plotted against SMPS aerosol mass concentration for the periods of approximately constant aerosol 
mass during the experiment described above. The measured ROS concentration showed strong positive linear correlation with aerosol mass, likely due to the highly oxidised nature of the SOA produced.

The limit of detection (LOD) was determined via considering signal stability during an extended period of constant exposure. Zero-grade synthetic air (BOC) was sampled for a period of $7 \mathrm{~h}$, and 3 times the standard deviation of measurement over this time period gave a working LOD of $3.85 \mathrm{nmol}$ $\left[\mathrm{H}_{2} \mathrm{O}_{2}\right]$ equivalents per $\mathrm{m}^{3}$ air. This figure differs from those stated by others describing DCFH-HRP ROS detection techniques, but this is likely due to varied methods of particle capture, detection and LOD calculation (King and Weber, 2013; Wang et al., 2011). As observed in Figs. 6 and 7, the OPROSI is sensitive enough to show significant response to changes in sample aerosol mass of less than $5 \mu \mathrm{g} \mathrm{m}^{-3}$, which suggests sensitivity suitable for ambient conditions.

The time resolution can be determined by considering the time it takes for the OPROSI detector signal to transit from one concentration plateau to another upon an instantaneous change in sample concentration. This transition time is $\leq 12 \mathrm{~min}$, regardless of whether these changes are due to transition between measuring two different sample concentrations or due to transition between a blank measurement and a sample measurement (through introduction and removal of the HEPA filter). Thus, $12 \mathrm{~min}$ is a suitable maximum value for OPROSI time resolution, as tested up to $425 \mu \mathrm{g} \mathrm{m}^{-3}$ oxidised SOA. This time resolution should be sufficient to resolve most expected ROS concentration changes in the ambient atmosphere.

\subsection{Ambient measurement of particle-bound ROS at an urban roadside site using the OPROSI}

Figure 8 shows an example of ROS data during a wintertime ambient measurement campaign at a Department of Environment Food and Rural Affairs (Defra) Automatic Urban and Rural Network (AURN) roadside measurement site on Marylebone Road, London, UK. Measurements were taken via a $360^{\circ}$ inlet, $\sim 1 \mathrm{~m}$ away from and $\sim 4 \mathrm{~m}$ above, the edge of the roadside. $\mathrm{PM}_{2.5}$ levels were recorded by Defra using a filter dynamics measurement system-tapered element oscillating microbalance (FDMS-TEOM).

The gaps in the data shown in Fig. 8 correspond to periods when extended blank measurements were taken. Data from this campaign show that our new instrument is sensitive enough to detect changes in ambient ROS levels at a polluted urban site in the UK and can measure over a period of $24 \mathrm{~h}$ with minimal user interaction (as discussed above). ROS concentrations of 4-24 nmol $\left[\mathrm{H}_{2} \mathrm{O}_{2}\right]$ equivalents per $\mathrm{m}^{3}$ air were measured during a $\sim 24 \mathrm{~h}$ period with $\mathrm{PM}_{2.5}$ concentrations of 5-28 $\mu \mathrm{g} \mathrm{m}^{-3}$ and a range of $0.4-2.7 \mathrm{nmol}\left[\mathrm{H}_{2} \mathrm{O}_{2}\right]$ equivalents per microgram $(\mu \mathrm{g})\left[\mathrm{PM}_{2.5}\right]$. When comparing these AURN PM 2.5 data to the ROS data, there does appear to be a potentially weak correlation of their general trends

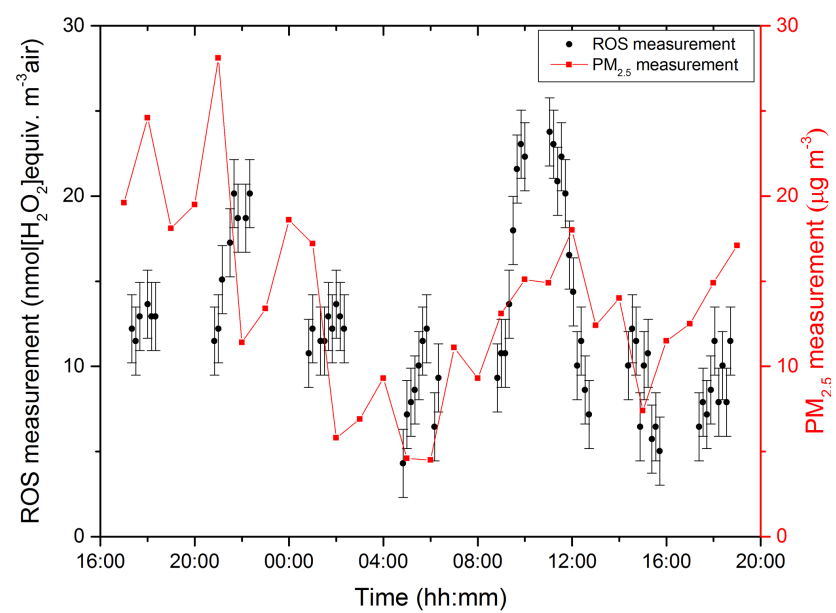

Figure 8. $\mathrm{A} \sim 24 \mathrm{~h}$ time series of ambient ROS measurement from an urban roadside site in central London, UK (Marylebone Road). Black circles represent $10 \mathrm{~min}$ averages of OPROSI data (nmol $\left[\mathrm{H}_{2} \mathrm{O}_{2}\right]$ equivalents per $\mathrm{m}^{3}$ air); error bars span $1 \times$ LOD. Red squares show hourly averages of $\mathrm{PM}_{2.5}\left(\mu \mathrm{g} \mathrm{m}^{-3}\right)$.

throughout the $24 \mathrm{~h}$ period. Further measurements will be undertaken during periods of higher photochemistry, i.e. in summertime, to see what effect this has on the correlation between ROS measurements and $\mathrm{PM}_{2.5}$ data.

Our recorded ROS concentration of 4-24 nmol $\left[\mathrm{H}_{2} \mathrm{O}_{2}\right]$ equivalents per $\mathrm{m}^{3}$ air is comparable in magnitude to that found by Wang et al. (2011) during their 2011 study in Rochester, New York, USA, in which they stated an average ROS concentration of $8.3 \pm 2.19 \mathrm{nmol}\left[\mathrm{H}_{2} \mathrm{O}_{2}\right]$ equivalents per $\mathrm{m}^{3}$ air over a period of 7 days; a further three out of the five other studies mentioned therein were also comparable, with average campaign values ranging 5.71$15.10 \mathrm{nmol}\left[\mathrm{H}_{2} \mathrm{O}_{2}\right]$ equivalents per $\mathrm{m}^{3}$ air. King and Weber (2013), however, mentioned a number of measurements below their limit of detection and stated an average ROS concentration of $0.26 \mathrm{nmol}\left[\mathrm{H}_{2} \mathrm{O}_{2}\right]$ equivalents per $\mathrm{m}^{3}$ air for their urban site in Atlanta, USA. At present it is difficult to determine whether these ROS concentration differences are due to the location studied, sample studied or differences in instrument design.

\section{Conclusions}

A compact instrument, OPROSI, has been designed and built to be capable of continuous automated and unattended quantification of particle-bound reactive oxygen species over many hours using the DCFH-HRP assay. It is contained within a metal shell for ease of transportation and field measurement deployment. The OPROSI was designed with a view to making the instrument automated for long periods of time, as well as to detecting changes over a timescale of minutes, and will therefore be suitable for health-related air 
pollution studies as well as for atmospheric process studies. The instrument uses mild aerosol extraction conditions that should reduce measurement artefacts due to decomposition of labile ROS components. It has a detection limit of $3.85 \mathrm{nmol}\left[\mathrm{H}_{2} \mathrm{O}_{2}\right]$ equivalent per $\mathrm{m}^{3}$ air and a time resolution estimate of $\leq 12 \mathrm{~min}$ with laboratory-generated oxidised aerosol. The OPROSI has shown capability of several days' successful continual functionality with minimal user interaction (refilling liquid bottles, emptying waste bottle and daily replacement of the filter within the particle collector) and 12$14 \mathrm{~h}$ sample measurement with no user interaction required.

The new instrument was tested with laboratory-generated oxidised SOA via $\alpha$-pinene ozonolysis and showed clear correlation between ROS intensity and oxidised-SOA mass, in a range suggesting suitability for ambient, laboratory and chamber measurements. Ambient measurements were taken at an urban site in London, UK, which confirmed the OPROSI is sensitive enough for ambient ROS measurement.

\section{Data availability}

Data can be made available upon requests to the corresponding author.

Author contributions. Markus Kalberer conceived the study and oversaw research. Stephen J. Fuller developed the initial technique. Francis P. H. Wragg designed and developed the instrument, designed and performed the experiments, analysed the data, and wrote the manuscript. Ray Freshwater designed and built many of the electronic components required to run the instrument. David C. Green and Frank J. Kelly facilitated access to the Marylebone Road site in London and provided the $\mathrm{PM}_{2.5}$ data. All authors have read and approved the final manuscript.

Acknowledgements. The authors would like to thank ERC (the European Research Council, grant no. 279405) for their funding of this study. Infrastructure at Marylebone Road was supported by NERC (the Natural Environment Research Council, Clearflo grant no. NE/H003231/1) and Defra (Department of Environment Food and Rural Affairs, contract AQ0643 Automatic London Network (2010-14) RMP 5442). Thanks also to Keith Gray, Richard Nightingale and colleagues for their help with various custom-built components and incorporation into the final instrument structure.

Edited by: P. Herckes

Reviewed by: three anonymous referees

\section{References}

Borm, P. J. A., Kelly, F., Kunzli, N., Schins, R. P. F., and Donaldson, K.: Oxidant generation by particulate matter: from biologically effective dose to a promising, novel metric, Occup. Environ. Med., 64, 73-74, 2007.

Brunekreef, B. and Holgate, S. T.: Air pollution and health, Lancet, 360, 1233-1242, 2002.

Docherty, K. S., Wu, W., Lim, Y. B., and Ziemann, P. J.: Contributions of organic peroxides to secondary aerosol formed from reactions of monoterpenes with O-3, Environ. Sci. Technol., 39, 4049-4059, 2005.

Dockery, D. W., Pope, C. A., Xu, X. P., Spengler, J. D., Ware, J. H., Fay, M. E., Ferris, B. G., and Speizer, F. E.: An Association Between Air-Pollution and Mortality in 6-United-States Cities, New. Engl. J. Med., 329, 1753-1759, 1993.

Donaldson, K., Stone, V., Borm, P. J. A., Jimenez, L. A., Gilmour, P. S., Schins, R. P. F., Knaapen, A. M., Rahman, I., Faux, S. P., Brown, D. M., and MacNee, W.: Oxidative stress and calcium signaling in the adverse effects of environmental particles $\left(\mathrm{PM}_{10}\right)$, Free Radical Bio. Med., 34, 1369-1382, 2003.

Fuller, S. J., Wragg, F. P. H., Nutter, J., and Kalberer, M.: Comparison of on-line and off-line methods to quantify reactive oxygen species (ROS) in atmospheric aerosols, Atmos. Environ., 92, 97103, 2014

Godri, K. J., Green, D. C., Fuller, G. W., Dall'Osto, M., Beddows, D. C., Kelly, F. J., Harrison, R. M., and Mudway, I. S.: Particulate Oxidative Burden Associated with Firework Activity, Environ. Sci. Technol., 44, 8295-8301, 2010.

Godri, K. J., Harrison, R. M., Evans, T., Baker, T., Dunster, C., Mudway, I. S., and Kelly, F. J.: Increased Oxidative Burden Associated with Traffic Component of Ambient Particulate Matter at Roadside and Urban Background Schools Sites in London, Plos One, 6, p. 11, 2011.

Hart, J. E., Liao, X. M., Hong, B. L., Puett, R. C., Yanosky, J. D., Suh, H., Kioumourtzoglou, M. A., Spiegelman, D., and Laden, F.: The association of long-term exposure to $\mathrm{PM}_{2.5}$ on all-cause mortality in the Nurses' Health Study and the impact of measurement-error correction, Environ. Health, 14, p. 9, 2015.

Hasson, A. S. and Paulson, S. E.: An investigation of the relationship between gas-phase and aerosol-borne hydroperoxides in urban air, J. Aerosol Sci., 34, 459-468, 2003.

Jimenez, J. L., Canagaratna, M. R., Donahue, N. M., Prevot, A. S. H., Zhang, Q., Kroll, J. H., DeCarlo, P. F., Allan, J. D., Coe, H., Ng, N. L., Aiken, A. C., Docherty, K. S., Ulbrich, I. M., Grieshop, A. P., Robinson, A. L., Duplissy, J., Smith, J. D., Wilson, K. R., Lanz, V. A., Hueglin, C., Sun, Y. L., Tian, J., Laaksonen, A., Raatikainen, T., Rautiainen, J., Vaattovaara, P., Ehn, M., Kulmala, M., Tomlinson, J. M., Collins, D. R., Cubison, M. J., Dunlea, E. J., Huffman, J. A., Onasch, T. B., Alfarra, M. R., Williams, P. I., Bower, K., Kondo, Y., Schneider, J., Drewnick, F., Borrmann, S., Weimer, S., Demerjian, K., Salcedo, D., Cottrell, L., Griffin, R., Takami, A., Miyoshi, T., Hatakeyama, S., Shimono, A., Sun, J. Y., Zhang, Y. M., Dzepina, K., Kimmel, J. R., Sueper, D., Jayne, J. T., Herndon, S. C., Trimborn, A. M., Williams, L. R., Wood, E. C., Middlebrook, A. M., Kolb, C. E., Baltensperger, U., and Worsnop, D. R.: Evolution of Organic Aerosols in the Atmosphere, Science 326, 1525-1529, 2009. 
Kelly, F. J. and Fussell, J. C.: Size, source and chemical composition as determinants of toxicity attributable to ambient particulate matter, Atmos. Environ. 60, 504-526, 2012.

King, L. E. and Weber, R. J.: Development and testing of an online method to measure ambient fine particulate reactive oxygen species (ROS) based on the 2',7'-dichlorofluorescin (DCFH) assay, Atmos. Meas. Tech., 6, 1647-1658, doi:10.5194/amt-61647-2013, 2013.

Koike, E. and Kobayashi, T.: Chemical and biological oxidative effects of carbon black nanoparticles, Chemosphere 65, 946-951, 2006.

Kramer, A. J., Rattanavaraha, W., Zhang, Z., Gold, A., Surratt, J. D., and Lin, Y.-H.: Assessing the oxidative potential of isoprenederived epoxides and secondary organic aerosol, Atmos. Environ., 130, 211-218, 2016.

Kroll, J. H. and Seinfeld, J. H.: Chemistry of secondary organic aerosol: Formation and evolution of low-volatility organics in the atmosphere, Atmos. Environ., 42, 3593-3624, 2008.

Kunzi, L., Mertes, P., Schneider, S., Jeannet, N., Menzi, C., Dommen, J., Baltensperger, U., Prevot, A. S. H., Salathe, M., Kalberer, M., and Geiser, M.: Responses of lung cells to realistic exposure of primary and aged carbonaceous aerosols, Atmos. Environ. 68, 143-150, 2013.

Laden, F., Schwartz, J., Speizer, F. E., and Dockery, D. W.: Reduction in fine particulate air pollution and mortality - Extended follow-up of the Harvard six cities study, Am. J. Resp. Crit. Care, 173, 667-672, 2006.

Lee, A., Goldstein, A. H., Keywood, M. D., Gao, S., Varutbangkul, V., Bahreini, R., Ng, N. L., Flagan, R. C., and Seinfeld, J. H.: Gas-phase products and secondary aerosol yields from the ozonolysis of ten different terpenes, J. Geophys. Res.-Atmos., 111, D07302, doi:10.1029/2005JD006389, 2006.

Lepeule, J., Laden, F., Dockery, D., and Schwartz, J.: Chronic Exposure to Fine Particles and Mortality: An Extended Follow-up of the Harvard Six Cities Study from 1974 to 2009, Environ. Health Persp., 120, 965-970, 2012.

MacNee, W. and Donaldson, K.: Mechanism of lung injury caused by $\mathrm{PM}_{10}$ and ultrafine particles with special referance to COPD, Eur. Respir. J., 2, 47S-51S, 2003.

Mertes, P., Pfaffenberger, L., Dommen, J., Kalberer, M., and Baltensperger, U.: Development of a sensitive long path absorption photometer to quantify peroxides in aerosol particles (PeroxideLOPAP), Atmos. Meas. Tech., 5, 2339-2348, doi:10.5194/amt5-2339-2012, 2012.

Morio, L. A., Hooper, K. A., Brittingham, J., Li, T. H., Gordon, R. E., Turpin, B. J., and Laskin, D. L.: Tissue injury following inhalation of fine particulate matter and hydrogen peroxide is associated with altered production of inflammatory mediators and antioxidants by alveolar macrophages, Toxicol. Appl. Pharm., 177, 188-199, 2001

Oberdorster, G., Oberdorster, E., and Oberdorster, J.: Nanotoxicology: An emerging discipline evolving from studies of ultrafine particles, Environ. Health Persp., 113, 823-839, 2005.
Pryor, W. A. and Church, D. F.: Aldehydes, Hydrogen-Peroxide, and Organic Radicals as Mediators of Ozone Toxicity, Free Radical Bio. Med., 11, 41-46, 1991.

Puett, R. C., Hart, J. E., Yanosky, J. D., Spiegelman, D., Wang, M. L., Fisher, J. A., Hong, B. L., and Laden, F.: Particulate Matter Air Pollution Exposure, Distance to Road, and Incident Lung Cancer in the Nurses' Health Study Cohort, Environ. Health Persp., 122, 926-932, 2014.

Steenhof, M., Gosens, I., Strak, M., Godri, K. J., Hoek, G., Cassee, F. R., Mudway, I. S., Kelly, F. J., Harrison, R. M., Lebret, E., Brunekreef, B., Janssen, N. A. H., and Pieters, R. H. H.: In vitro toxicity of particulate matter (PM) collected at different sites in the Netherlands is associated with PM composition, size fraction and oxidative potential - the RAPTES project, Part. Fibre Toxicol., 8, p. 15, 2011.

Stevanovic, S., Miljevic, B., Surawski, N. C., Fairfull-Smith, K. E., Bottle, S. E., Brown, R., and Ristovski, Z. D.: Influence of Oxygenated Organic Aerosols (OOAs) on the Oxidative Potential of Diesel and Biodiesel Particulate Matter, Environ. Sci. Technol., 47, 7655-7662, 2013.

Takeuchi, M., Ullah, S. M. R., Dasgupta, P. K., Collins, D. R., and Williams, A.: Continuous collection of soluble atmospheric particles with a wetted hydrophilic filter, Anal. Chem., 77, 80318040, 2005.

Tong, H., Arangio, A. M., Lakey, P. S. J., Berkemeier, T., Liu, F., Kampf, C. J., Brune, W. H., Pöschl, U., and Shiraiwa, M.: Hydroxyl radicals from secondary organic aerosol decomposition in water, Atmos. Chem. Phys., 16, 1761-1771, doi:10.5194/acp-161761-2016, 2016.

Venkatachari, P., Hopke, P. K., Grover, B. D., and Eatough, D. J.: Measurement of particle-bound reactive oxygen species in $\mathrm{Ru}-$ bidoux aerosols, J. Atmos. Chem., 50, 49-58, 2005.

Verma, V., Pakbin, P., Cheung, K. L., Cho, A. K., Schauer, J. J., Shafer, M. M., Kleinman, M. T., and Sioutas, C.: Physicochemical and oxidative characteristics of semi-volatile components of quasi-ultrafine particles in an urban atmosphere, Atmos. Environ., 45, 1025-1033, 2011.

Vesna, O., Sax, M., Kalberer, M., Gaschen, A., and Ammann, M.: Product study of oleic acid ozonolysis as function of humidity, Atmos. Environ., 43, 3662-3669, 2009.

Wang, D. B., Pakbin, P., Shafer, M. M., Antkiewicz, D., Schauer, J. J., and Sioutas, C.: Macrophage reactive oxygen species activity of water-soluble and water-insoluble fractions of ambient coarse, $\mathrm{PM}_{2.5}$ and ultrafine particulate matter (PM) in Los Angeles, Atmos. Environ., 77, 301-310, 2013.

Wang, Y., Hopke, P. K., Sun, L., Chalupa, D. C., and Utell, M. J.: Laboratory and field testing of an automated atmospheric particle-bound reactive oxygen species sampling-analysis system, J. Toxicol., 2011, 419476, doi:10.1155/2011/419476, 2011

Ziemann, P. J.: Aerosol products, mechanisms, and kinetics of heterogeneous reactions of ozone with oleic acid in pure and mixed particles, Faraday Discuss., 130, 469-490, 2005. 